\title{
On-pump or off-pump? Right debate, but wrong question!
}

Antonio M. Calafiore, MD, ${ }^{a}$ and Michele Di Mauro, $\mathrm{MD}, \mathrm{PhD}^{\mathrm{b}}$

From the ${ }^{\mathrm{a} D e p a r t m e n t}$ of Cardiac Surgery, John Paul II Foundation, Campobasso, Italy; and ${ }^{\mathrm{b}}$ Department of Cardiovascular Disease, University of L'Aquila, L'Aquila, Italy.

Disclosures: Authors have nothing to disclose with regard to commercial support.

Received for publication March 21, 2018; accepted for publication March 23, 2018; available ahead of print May 3, 2018.

Address for reprints: Antonio M. Calafiore, MD, Department of Cardiac Surgery Pope John Paul II Foundation, Campobasso, Italy (E-mail: am.calafiore@gmail.com).

J Thorac Cardiovasc Surg 2018;156:984-5

$0022-5223 / \$ 36.00$

Copyright (C) 2018 by The American Association for Thoracic Surgery

https://doi.org/10.1016/j.jtcvs.2018.03.090

Ueki and colleagues ${ }^{1}$ report the results of an impressive cohort of patients with chronic renal failure (CRF) who underwent either on-pump coronary artery bypass grafting (ONCAB) or off-pump coronary artery bypass grafting (OPCAB). The latter showed significant reduction of early mortality and prevalence of composite events (mortality and major morbidity) in both overall population and subset of patients with moderate or severe CRF or with preoperative dialysis. The convincing results of the study support the use of OPCABG in patients with CRF.

Since the 1990s there has been huge interest in OPCAB because cardiopulmonary bypass was believed to be harmful for patients with atherosclerosis. The results of the first reports- mostly observational and limited to the early postoperative period-were dramatically in favor of OPCAB in terms of reduction of mortality and morbidity. With time, the debate became more analytic and the replacement of unmatched observational studies with propensity-matched studies and randomized controlled trials (RCTs) allowed a more valid understanding of the benefits and the limits of both techniques. The progress of cardiopulmonary bypass during past years and the increased quality of perioperative management improved the results of ONCAB, whereas OPCAB remained stable. It is hard to summarize the findings because conflicting results are reported even in the most recent articles. In general, propensity-matched studies that include all patients, independently from the risk, better reflect the real world, whereas RCTs tend to include selected patients with low or medium risk, making it difficult for the right perspective to be given to the conclusions.

A recent meta-analysis that included 1.2 million patients at mostly low and medium risk confirmed that long-term survival after OPCAB seems to be lower than ONCAB. ${ }^{2}$ On the other side, there is evidence that high-risk patients can benefit from OPCAB. ${ }^{1,3,4}$

The right target of the debate is this: Because there are some subgroups of patients who can benefit more from OP$\mathrm{CAB}$, how is it possible to appropriately train surgeons? In the analysis of the 5-year results of the Arterial

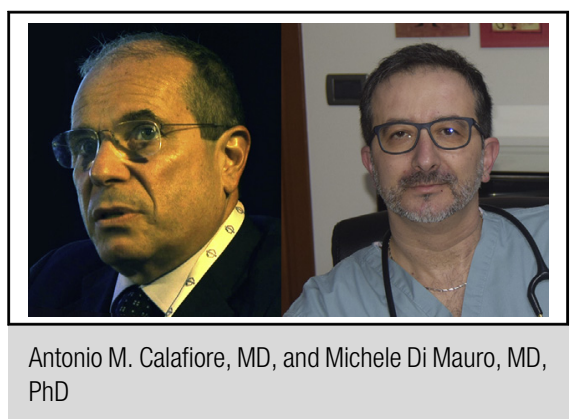

\section{Central Message}

The good results reported in RCTs are due to the expertise of OPCAB surgeons, very likely not to the effectiveness of the technique. Ueki and colleagues ${ }^{1}$ push us hard to find a solution.

See Article page 976

Revascularization Trial, ${ }^{5}$ most $\mathrm{OPCAB}$ cases were performed by 3 surgeons with optimal results. On the contrary, patients who underwent OPCAB performed by surgeons with a low number of cases had higher mortality. ${ }^{5,6}$

This statement is confirmed by the results of recent trials comparing OPCAB with ONCAB. A main criticism of the Veterans Affairs Randomized On/Off Bypass (ROOBY) $\mathrm{Trial}^{7}$ is related to the low threshold used to define a surgeon's experience; that is, those who had performed only $\geq 20$ off-pump cases. This bias very likely impaired either early or late results of OPCAB. The CABG Off or On Pump Revascularization Study (CORONARY) study overcame this issue by enrolling surgeons who had performed more than 100 OPCAB procedures in 2 years. ${ }^{8}$ In the German Off-Pump Coronary Artery Bypass Grafting in Elderly Patients (GOPCABE) study, ${ }^{9}$ surgeons were defined as expert with an average of 514 OPCAB procedures performed.

Data from an enormous cohort of patients undergoing isolated coronary artery bypass grafting $(\mathrm{N}=2,094,094$ patients from the Nationwide Inpatient Sample from 2003 to 2011) suggest that results of OPCAB depend on the volume not only of the center, but also of the single surgeon. ${ }^{6}$ Inevitably the price to pay to obtain a better outcome in high-risk patients is a possible worse outcome in low-risk patients. The good results reported in RCTs are due to the expertise of surgeons who are performing OPCAB, very likely not to the effectiveness of the technique.

This is the real conundrum, where the debate has to be driven. The study from Ueki and colleagues, ${ }^{1}$ with its stringent conclusions, pushes us hard to find a solution. 


\section{References}

1. Ueki C, Miyata H, Motomura N, et al. Off-pump technique reduces operative mortality after elective coronary artery bypass grafting in patients with preoperative renal failure. J Thorac Cardiovasc Surg. 2018;156:976-83.

2. Filardo G, Hamman BL, da Graca B, Sass DM, Machala NJ, Ismail S, et al. Efficacy and effectiveness of on- versus off-pump coronary artery bypass grafting: a meta-analysis of mortality and survival. J Thorac Cardiovasc Surg. 2018;155: 172-9.e5.

3. Benedetto U, Angelini GD, Caputo M, Feldman DN, Kim LK, Lau C, et al. Off- vs. on-pump coronary artery bypass graft surgery on hospital outcomes in 134,117 octogenarians. J Thorac Dis. 2017;9:5085-92.

4. Benedetto U, Caputo M, Vohra H, Davies A, Hillier J, Bryan A, et al. Off-pump versus on-pump coronary artery bypass surgery in patients with actively treated diabetes and multivessel coronary disease. J Thorac Cardiovasc Surg. 2016; 152:1321-30.e12.

5. Benedetto U, Altman DG, Gerry S, Gray A, Lees B, Flather M, et al. Off-pump versus on-pump coronary artery bypass grafting: insights from the Arterial Revascularization Trial. J Thorac Cardiovasc Surg. 2018;155:1545-53.e7.

6. Benedetto U, Lau C, Caputo M, Kim L, Feldman DN, Ohmes LB, et al. Comparison of outcomes for off-pump versus on-pump coronary artery bypass grafting in low-volume and high-volume centers and by low-volume and high-volume surgeons. Am J Cardiol. 2018;121:552-7.

7. Shroyer AL, Hattler B, Wagner TH, Collins JF, Baltz JH, Quin JA, et al. Five-year outcomes after on-pump and off-pump coronary-artery bypass. $N$ Engl J Med. 2017;377:623-32.

8. Lamy AR, Devereaux PJ, Yusuf S. Five-year outcomes after off-pump or on-pump coronary-artery bypass grafting. N Engl J Med. 2017;376:894-5.

9. Diegeler A, Börgermann J, Kappert U, Breuer M, Böning A, Ursulescu A, et al Off-pump versus on-pump coronary-artery bypass grafting in elderly patients. $N$ Engl J Med. 2013;368:1189-98. 